\title{
Conditioning of the rabbit nictitating membrane response: ISI by ITI interaction*
}

\author{
FREDERICK W. MIS, JAMES G. ANDREWS, and W. RONALD SALAFIA \\ Fairfield University, Fairfield, Conn. 06430
}

Sixty-six rabbits were employed to investigate the effects of two constant ITIs ( 1 and $5 \mathrm{~min})$ and three ISIs $(300,1,000$, and $2,000 \mathrm{msec})$ on conditioning of the nictitating membrane response. Conditioning rates were found to be directly related to both the ISI and an ISI by ITI interaction. Results were attributed to differences in ITI consolidation rates and differential vulnerability of the consolidation process to disruption. Furthermore, the use of constant ITIs suggested relationships that may have been obscured in the past by the use of variable ITIs.

Results of studies aimed at identifying the relationship between intertrial interval (ITI) and acquisition in classical conditioning have been at best contradictory. Several investigators have found no relationship at relatively low ITIs (Prokasy \& Whaley, 1961) or relatively high ITIs (Baron, 1952), while others have found a direct relationship between length of ITI and speed of acquisition in both humans (Spence \& Norris, 1950) and infrahumans (Gormezano, 1966; Salafia \& Mis, 1970).

Unfortunately, most previous ITI investigations have used human Ss, with the problems inherent in their use, such as voluntary responding and spontaneous blinking. Moreover, the use of variable ITIs in previous studies might have obscured some effects that could emerge with the use of constant ITIs. These difficulties were averted in one recent experiment (Salafia \& Mis, 1970) using the rabbit nictitating membrane response (NMR) which involved a parametric evaluation of two interstimulus intervals (ISIs), namely 250 and $750 \mathrm{msec}$, orthogonal to eight constant ITIs ranging from 5 to $120 \mathrm{sec}$. The results of the study indicated a relatively smooth increase in rate of conditioning with increasing ITI at the 250-msec ISI, while at 750 -msec ISI there was a smooth increase in conditioning rate up to a 45-sec ITI, a sharp decrease at $60 \mathrm{sec}$, a sharp return at $75 \mathrm{sec}$, and then asymptotic performance. These investigators offered a consolidation interpretation of their data and suggested that the 60 -sec ITI decrement was due to a state of differential vulnerability of the consolidation process to disruption at that point.

*This research was supported by NSF Grant GY-55-33 to W. Ronald Salafia. The authors wish to express their appreciation to J. Oakey McKnight for his assistance duri. $z$ the final stages of the study. Please address reprint requests to Dr. Salafia.
The present study is a further evaluation of the effects of ISI and constant ITI manipulations. Optimal, intermediate, and nonoptimal ISI levels were tested at two relatively long ITIs.

\section{SUBJECTS}

The Ss were 72 naive male and female rabbits of mixed breed, 70 to 100 days old at the start of the experiment. They were housed in like-sexed pairs and maintained on ad lib food and water. Six Ss were excluded due to illness or eye infections that became evident during experimentation, leaving a total $\mathrm{N}$ of 66 , varying from 10 to 12 Ss per group.

\section{APPARATUS}

Four rabbits were run concurrently in a soundproof room containing four separate cubicles, each serviced by independent control and recording equipment located in an adjoining room. A panel in front of each $S$ contained two impedence-matched speakers, used to present continuous white noise for masking during the ITI as well as the $1,000-\mathrm{Hz}$ CSs.

Animals were placed in Plexiglas

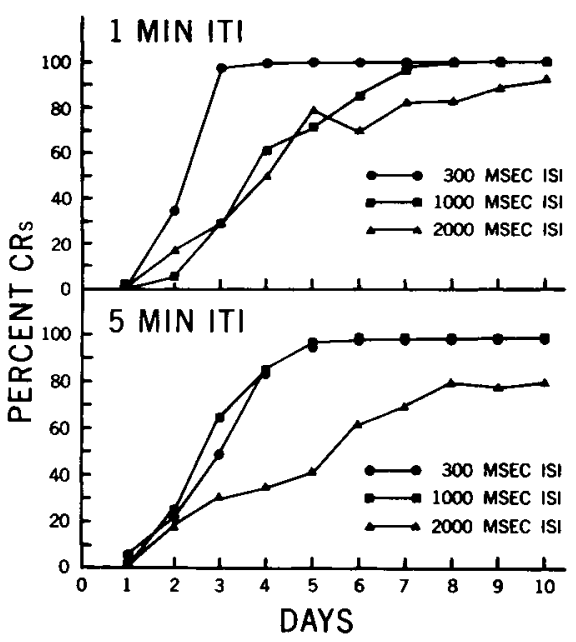

Fig. 1. Acquisition curves over 10 days of conditioning at 15 trials per day. restraining boxes. Tailor hooks attached to adjustable velcro straps served as eyelid retractors and UCS electrodes. The UCS consisted of a $3-\mathrm{mA}, 60-\mathrm{Hz}$ shock delivered for $50 \mathrm{msec}$. Movements of the nictitating membrane were monitored by a photoelectric transducer mounted on each S's head by means of a muzzle-like assembly and mechanically coupled to a surgical suture in the membrane. Signals from the transducers were amplified and graphically recorded by a Grass 5D polygraph. A CR was defined as a pen deflection of at least $1 \mathrm{~mm}$, occurring at least $50 \mathrm{msec}$ after CS onset but before UCS onset. Apparatus and procedures similar to the above have been described and illustrated in detail by Gormezano (1966).

\section{PROCEDURE}

Twenty-four hours prior to the first experimental session, Ss were prepared by having a surgical silk loop tied into the nictitating membrane of the right eye. Ss were then placed in the experimental cubicles, with the white noise on, for a 15-min habituation period, after which they were assigned in a balanced (by sex and breed) order to one cell of a 2 by 3 factorial design, with constant ITIs of 1 or $5 \mathrm{~min}$ and ISIs of $300,1,000$, or $2,000 \mathrm{msec}$.

Conditioning sessions began on the day following habituation and continued, one per day for 10 days or until a criterion of two successive sessions with no less than 90\% CRs was reached. When criterion was reached, performance on the second criterion day was extrapolated over the remaining 10 days. Each conditioning session consisted of preparing $S s$ as described above and then presenting 15 CS-UCS pairings at the ITI and ISI appropriate to the cell to which the animals had been assigned.

\section{RESULTS}

The acquisition curves for the six experimental groups are presented in Fig. 1. The nature of the acquisition function is clearly dependent upon ISI and ITI. However, there is not a simple relationship, and three general trends may be seen. First, for the 300- and 2,000-msec ISIs, acquisition was poorer at the longer ITI than at the shorter one. Second, at the $1,000-\mathrm{msec}$ ISI, the reverse effect occurred, with acquisition rate at the 5-min ITI superior to that at the $1-\mathrm{min}$ ITI. Third, the performance of the $1,000-\mathrm{msec}$ group approximated that of the 2,000 -msec group at a $1-\mathrm{min}$ ITI, while at the 5 -min ITI it was almost identical to that of the 300 -msec group. Thus, at these values, ISI appears to interact with ITI in determining performance.

Two mixed factorial analyses of variance 
(Lindquist, 1953) were computed on the data. The first, a 2 by 3 by 10 analysis on the data for all 10 days of experimentation and the second, a 2 by 3 by 5 analysis on only the first 5 days. The purpose of the partial analysis was to have a separate evaluation of the early stages of acquisition during which the greatest differences occurred.

The 2 by 3 by 10 analysis revealed no significant ITI main effect $(F<1)$ but a very significant ISI effect $(F=15.22$, $\mathrm{df}=2 / 60, \quad \mathrm{p}<.001)$ and ISI by ITI interaction $(\mathrm{F}=3.35, \mathrm{df}=2 / 60, \mathrm{p}<.05)$. In addition, there was the expected learning session effect $(F=258.10$, $\mathrm{df}=9 / 600, \quad \mathrm{p}<.001$ ) and interactions: Sessions by ISI ( $F=6.81$, df $=18 / 600$, $\mathrm{p}<.001$ ) and Sessions by ISI by ITI $(F=7.46, \quad \mathrm{df}=18 / 600, \mathrm{p}<.001)$. The 2 by 3 by 5 analysis revealed the same significant effects as noted above, but, as expected, the effects were stronger. Thus, the ISI by ITI interaction reached significance beyond the .01 level $(F=5.71$, $\mathrm{df}=2 / 60, \mathrm{p}<.01)$, while all other effects remained significant beyond the .001 level.

\section{DISCUSSION}

The finding of a significant decreasing trend in conditioning rates with increasing ISI is consistent with the classical eyeblink-conditioning literature with both human and infrahuman Ss (see Gormezano \& Moore, 1969 , p. 136 , for a summary of ISI studies). Therefore, this relationship will not be discussed at length, except to note that clearly this general trend is subject to specific fluctuations.

The finding of an ISI by ITI interaction cannot readily be compared to previous conditioning literature, because most of the previous work has been done with variable ITIs, has involved human eyelid conditioning, and has been done at shorter ITIs than those employed in the present study. Nor is the interaction interpretable in terms of most traditional hypotheses that tend to regard ISI and ITI effects as related to different behavioral, conceptual, or neural events.

The nature of the interaction may be seen in terms of the three trends. First, it would seem that under many conditions, extending the ITI to $5 \mathrm{~min}$ has a detrimental effect on acquisition rate. This may be seen for the 300 - and $2,000-\mathrm{msec}$ ISI groups where poorer conditioning occurred at the longer ITI, and this finding is consistent with that of Baron (1952) for human eyelid conditioning. In his study, Baron found that a $4.5-\mathrm{min}$ ITI group performed slightly more poorly than a $2-\mathrm{min}$ ITI group at $1,500-\mathrm{msec}$ ISI. These results suggest that there is an optimal range of times after CS-UCS presentation on a given trial during which the next pairing should occur, if it is to have maximum effect on learning.

The most unusual feature of the interaction was the reversal of conditioning rates at $1,000-\mathrm{msec}$ ISI. This reversal is reflected in two ways. First, the performance of the 5-min ITI group was superior to that of the 1-min ITI group. Second, a look at the acquisition curves reveals that at a 1 -min ITI, the $1,000-\mathrm{msec}$ ISI group closely approximated the performance of the 2,000-msec ISI group, while at the 5 -min ITI, the 1,000-msec group was almost identical in performance to the 300-msec group. Furthermore, at the 5-min ITI, the $1,000-\mathrm{msec}$ group performed slightly better than the 300-msec group. Even though this difference was small, it suggests that with very long ITIs there may be a shift in the "optimal" ISI.

These effects are not predictable from most previous models for ITI effects, such as Hull's (1952) response-produced inhibition hypothesis, Estes's (1955) stimulus-fluctuation hypothesis, or Prokasy's (1965) temporal-conditioning hypothesis. Prokasy's study is of particular interest because it was an attempt to evaluate the predictions of the other two hypotheses and was unable to provide unambiguous support for either formulation. Prokasy suggested that an alternative explanation was possible if it were assumed that the temporal distribution of trials could be a cue in the conditioning situation. Although the suggestion seems to have merit under some circumstances, Salafia \& Mis (1970) included three temporal-conditioning control groups in their study and found no evidence of temporal conditioning over 10 days at 15 trials per day, with constant ITIs of 5,60 , or $120 \mathrm{sec}$.

An alternative to the above hypotheses may be found in terms of a time-dependent consolidation process, in which there are differences in rate of consolidation and in vulnerability of the consolidation process to disruption (Papsdorf \& Kettlewell, 1968; Papsdorf, Levinthal, \& Salafia, 1969). Salafia \& Mis (1970) found that the consolidation hypothesis offered the most satisfactory explanation for their data and this hypothesis would seem to offer a plausible explanation for the interaction effects observed in the present study.

In summary, the results of a number of recent studies, including the present experiment, in which constant ITIs have been used, strongly suggest a view of many conditioning phenomena that differs from traditional views. A consolidation model for classical conditioning seems to offer considerable promise, although its usefulness needs to be established over a wider range of phenomena.

\section{REFERENCES}

BARON, M. R. The effect of long intertrial intervals on the limit of eyelid conditioning. Journal of Experimental Psychology, 1952, 44, 438-41.

ESTES, W. K. Statistical theory of distributional phenomena in learning. Psychological Review, 1955, 62, 145-154.

GORMEZANO, I. Classical conditioning. In J. B. Sidowski (Ed.), Experimental methods and instrumentation in psychology. New York: MeGraw-Hill, 1966. Pp. 385-420.

GORMEZANO, I., \& MOORE, J. W. Classical conditioning. In M. H. Marx (Ed.), Learning: Processes. New York: Macmillan, 1969. Pp. 119-203.

HULL, C. L. A behavior system. New Haven: Yale University Press, 1952.

LINDQUIST, E. F. Design and analysis of experiments in psychology and education. Boston: Houghton Mifflin, 1953.

PAPSDORF, J. D., LEVINTHAL, C. F., \& SALAFIA, W. R. Conditioning of the nictitating membrane response of the rabbit as a function of differential placement of interpolated stimuli in the intertrial interval. Paper presented at the meeting of the Eastern Psychological Association, Philadelphia, April 1969.

PAPSDORF, J. D., \& KETTLEWELL, N. M. The effects of different interpolated ITI stimulus-conditioned stimulus intervals on the acquisition of the classically conditioned nictitating membrane response of the rabbit. Psychonomic Science, 1968, 10, 171-172.

PROKASY, W. F. Stimulus fluctuation reactive inhibition, and time between trials in classical eyelid conditioning. Journal of Experimental Psychology, 1965, 70, 464-472.

PROKASY, W. F., \& WHALEY, F. L. Intertrial interval range shift in classical eyelid conditioning. Psychological Reports, 1963, 12, $55-58$.

SALAFIA, W. R., \& MIS, F. W. Intertrial interval consolidation in classical conditioning of the nictitating membrane response of the rabbit. Paper presented at the meeting of the Eastern Psychological Association, Atlantic City, April 1970.

SPENCE, K. W., \& NORRIS, E. B. Eyelid conditioning as a function of the intertrial interval. Journal of Experimental Psychology, 1950, 40, 716-720. 